\title{
Positive Outcomes Following a Multidisciplinary Approach in the Diagnosis and Prevention of Hospital Delirium
}

\author{
Jason Ching, MD, Sonja Darwish, MD, Keith Siegel, BA, Xi Li, MD, Jason Wong, MD, \\ Benjamin Simpson, MD, Spencer Funk, MD, and Olusinmi Bamgbose, MD
}

\begin{abstract}
Objectives: To reduce the incidence and duration of delirium among patients in a hospital ward through standardized delirium screening tools and nonpharmacologic interventions. To advance nursing-focused education on delirium-prevention strategies. To measure the efficacy of the interventions with the aim of reproducing best practices.
\end{abstract}

Background: Delirium is associated with poor patient outcomes but may be preventable in a significant percentage of hospitalized patients.

Methods: Following nursing-focused education to prevent delirium, we prospectively evaluated patient care outcomes in a consecutive series of patients who were admitted to a hospital medical-surgical ward within a 25 -week period. All patients who had at least 1 Confusion Assessment Method (CAM) documented by a nurse during hospitalization met our inclusion criteria ( $\mathrm{N}=353$ ). Standards for Quality Improvement Reporting Excellence guidelines were adhered to.

Results: There were 187 patients in the control group, and 166 in the postintervention group. Compared to the control group, the postintervention group had a significant decrease in the incidence of delirium during hospitalization $(14.4 \%$ vs 4.2\%) and a significant decrease in the mean percentage of tested nursing shifts with 1 or more positive CAM (4.9\% vs $1.1 \%)$. Significant differences in secondary outcomes between the control and postintervention groups included median length of stay ( 6 days vs 4 days), mean length of stay ( 8.5 days vs 5.9 days), and use of an indwelling urinary catheter $(9.1 \%$ vs $2.4 \%)$.

Conclusion: A multimodal strategy involving nursing-focused training and nonpharmacologic interventions to address hospital delirium is associated with improved patient care outcomes and nursing confidence. Nurses play an integral role in the early recognition and prevention of hospital delirium, which directly translates to reducing burdens in both patient functionality and health care costs.

Keywords: delirium; prevention; nurse; nursing; Confusion Assessment Method; hospital; precautions; nonpharmacologic; intervention. $\int$ elirium is a disorder characterized by inattention and acute changes in cognition. It is defined by the American Psychiatric Association's fifth edition of the Diagnostic and Statistical Manual of Mental Disorders as a disturbance in attention, awareness, and cognition over hours to a few days that is not better explained by a preexisting, established, or other evolving neurocognitive disorder. Delirium is common yet often under-recognized among hospitalized patients, particularly in the elderly. The incidence of delirium in elderly patients on admission is estimated to be $11 \%$ to $25 \%$, and an additional $29 \%$ to $31 \%$ of elderly patients will develop delirium during the hospitalization. ${ }^{2}$ Delirium costs the health care system an estimated $\$ 38$ billion to $\$ 152$ billion per year. ${ }^{3}$ It is associated with negative outcomes, such as increased new placements to nursing homes, increased mortality, increased risk of dementia, and further cognitive deterioration among patients with dementia. ${ }^{4-6}$

Despite its prevalence, delirium may be preventable in a significant percentage of hospitalized patients. Targeted intervention strategies, such as frequent reorientation,

From the Department of Neurology, Cedars-Sinai Medical Center, Los Angeles, CA (Drs. Ching, Darwish, Li, Wong, Simpson, and Funk), the Department of Anesthesia, Cedars-Sinai Medical Center, Los Angeles, CA (Keith Siegel), and the Department of Psychiatry, Cedars-Sinai Medical Center, Los Angeles, CA (Dr. Bamgbose). 


\section{Table 1. Order Set for Prevention of Hospital Delirium}

\begin{tabular}{|c|c|}
\hline Notify physician & $\begin{array}{l}\text { If patient has been newly screened positive on CAM } \\
\text { For sleep-promoting vital signs: Consider ordering vital signs to be taken } 3 \text { times a day between } \\
\text { 7:00 AM and 10:00 PM to promote sleep } \\
\text { Regarding patient tethers: Encourage early discontinuation of continuous cardiac monitoring, oxygen, } \\
\text { urinary catheter, and IV fluids (if tolerating fluids) } \\
\text { For HCT }<24 / \mathrm{Hgb} \\
\text { For low urine output ( }<400 \mathrm{~mL} / 24 \text { hours, BUN/creatinine ratio }>18 \text { ) } \\
\text { If bladder scan is }>300 \mathrm{~mL} \\
\text { If no bowel movement in past } 48 \text { hours } \\
\text { Temperature }>38.4^{\circ} \mathrm{C} \\
\text { Systolic blood pressure }<90 \mathrm{mmHg} \\
\text { Systolic blood pressure }>160 \mathrm{mmHg} \\
\text { Heart rate }<50 \text { bpm } \\
\text { Heart rate }>120 \text { bpm } \\
\text { Respiratory rate }<10 \text { breaths } / \mathrm{min} \\
\text { Respiratory rate }>30 \text { breaths } / \mathrm{min} \\
\text { Keep oxygen saturation } \geq 92\end{array}$ \\
\hline Out of bed & $\begin{array}{l}\text { Routine: } 3 \text { times daily } \\
\text { Specify: breakfast, lunch, dinner } \\
\text { Unless on bed rest }\end{array}$ \\
\hline Activity: ambulate & $\begin{array}{l}\text { Routine: } 3 \text { times daily } \\
\text { Unless on bed rest }\end{array}$ \\
\hline $\begin{array}{l}\text { Activity: bathroom with } \\
\text { assistance }\end{array}$ & $\begin{array}{l}\text { Routine: until discontinued } \\
\text { Unless on bed rest } \\
\text { No bedpans following surgery }\end{array}$ \\
\hline Perform CAM & Routine: every 12 hours \\
\hline $\begin{array}{l}\text { Measure orthostatic } \\
\text { vital signs }\end{array}$ & $\begin{array}{l}\text { Routine: daily } \\
\text { Patient position: supine, sitting, and standing }\end{array}$ \\
\hline Perform bladder scan & Routine: as needed \\
\hline Encourage by mouth fluids & $\begin{array}{l}\text { Routine: until discontinued } \\
\text { If cleared for by mouth liquids, encourage fluids/oral intake; fluids within reach of patient at all times }\end{array}$ \\
\hline Delirium protocol & $\begin{array}{l}\text { Routine: until discontinued } \\
\text { Notify pharmacy for review of medications if concern for American Geriatric Society Beers Criteria } \\
\text { medications and/or polypharmacy contributing to delirium } \\
\text { Reorient patient to location, day, and date during purposeful rounding } \\
\text { Sensory aids are to be used by patient during waking hours (ie, glasses, hearing aids, dentures) } \\
\text { Encourage family involvement (ie, bring objects from home, meal assist, conversation) } \\
\text { Educate family members about delirium } \\
\text { Daytime: blinds open, prevent napping, no caffeine after 12:00 PM, TV off when not in use } \\
\text { Nighttime: blinds closed/lights off, offer earplugs/eye mask, TV off, minimize interruptions } \\
\text { Nonpharmacologic sleep protocol: provide warm noncaffeinated drink, relaxing music }\end{array}$ \\
\hline $\begin{array}{l}\text { Call to volunteer services } \\
\text { assistance }\end{array}$ & $\begin{array}{l}\text { Routine: as needed } \\
\text { Specify for any of the following: } \\
\text { - Meal Time Mates: for patients who need assistance, encouragement, or company during meal times } \\
\text { - Transforming Care at the Bedside volunteer: for patients with minimal visitors. Note: not recommended } \\
\text { for patients with hyperactive delirium } \\
\text { - Other volunteer services: provide patient with therapeutic activities as appropriate for cognitive status } \\
\text { (ie, music therapy, pet therapy, activity apron, word games, playing cards, reiki, books) }\end{array}$ \\
\hline Consult to clinical dietitian & $\begin{array}{l}\text { Routine: } 1 \text { time for } 1 \text { occurrence } \\
\text { Reason for consult: nutritional evaluation }\end{array}$ \\
\hline Fall precautions & Routine: continuous \\
\hline Aspiration precautions & Routine: continuous \\
\hline
\end{tabular}




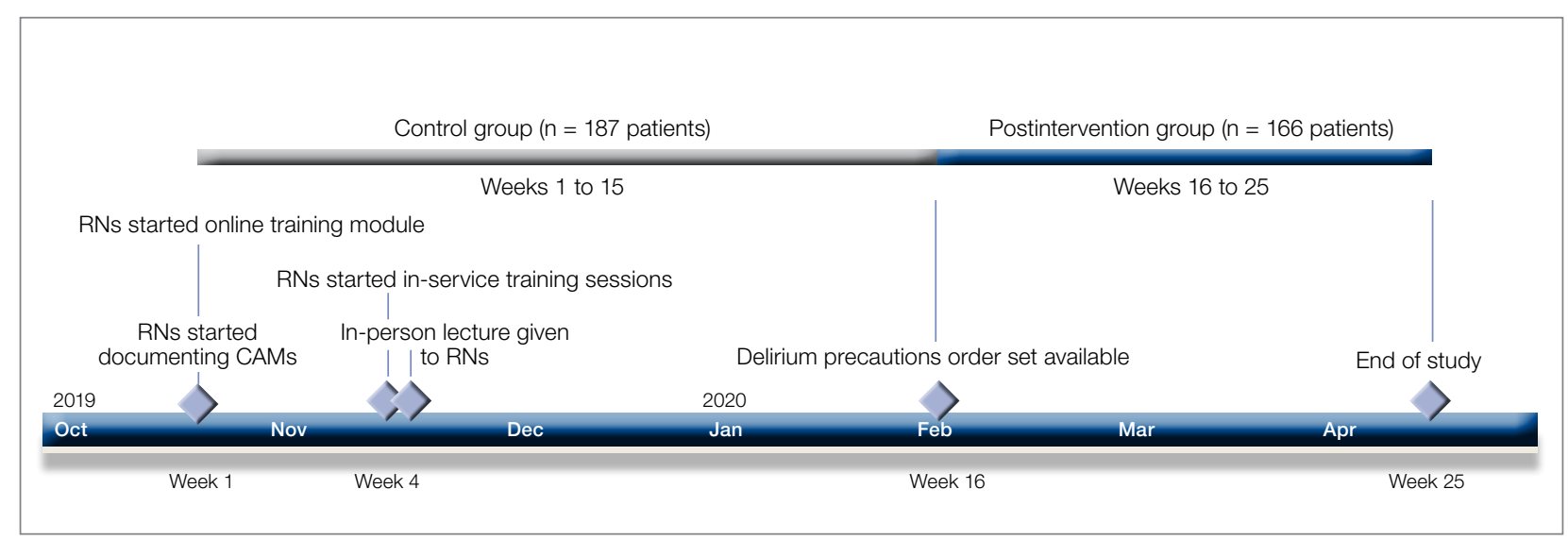

Figure 1. Timeline of study events. The gray bar represents the start of the training program (week 1) until the order set was made available (week 15). Patients admitted within this time period constituted our control group. The blue bar represents the 10 weeks after the completion of the interventions (weeks 16-25). Patients admitted within this time period constituted our postintervention group. Study interventions are marked with diamonds at the respective time course.

CAM, Confusion Assessment Method; RN, registered nurse.

maximizing sleep, early mobilization, restricting use of psychoactive medications, and addressing hearing or vision impairment, have been demonstrated to significantly reduce the incidence of hospital delirium. ${ }^{7,8}$ To achieve these goals, we explored the use of a multimodal strategy centered on nursing education. We integrated consistent, standardized delirium screening and nonpharmacologic interventions as part of a preventative protocol to reduce the incidence of delirium in the hospital ward.

\section{Methods}

We evaluated a consecutive series of patients who were admitted to a designated hospital medical-surgical ward within a 25-week period between October 2019 and April 2020. All patients during this period who had at least 1 Confusion Assessment Method (CAM) documented by a nurse during hospitalization met our inclusion criteria. Patients who did not have a CAM documented were excluded from the analysis. Delirium was defined according to the CAM diagnostic algorithm. ${ }^{9}$

Core nursing staff regularly assigned to the ward completed a multimodal training program designed to improve recognition, documentation, and prevention of hospital delirium. Prior to the training, the nurses completed a 5-point Likert scale survey assessing their level of confidence with recognizing delirium risk factors, preventing delirium, addressing delirium, utilizing the
CAM tool, and educating others about delirium. Nurses completed the same survey after the study period ended.

The training curriculum for nurses began with an online module reviewing the epidemiology and risk factors for delirium. Nurses then participated in a series of in-service training sessions led by a team of physicians, during which the CAM and nonpharmacologic delirium prevention measures were reviewed then practiced firsthand. Nursing staff attended an in-person lecture reviewing the current body of literature on delirium risk factors and effective nursing interventions. After formal training was completed, nurses were instructed to document CAM screens for each patient under their care at least once every 12-hour shift for the remainder of the study. An order set, reflected in Table 1, was made available to physicians and floor nurses to assist with implementing the educational components.

Patients admitted to the hospital unit from the start of the training program (week 1) until the order set was made available (week 15) constituted our control group. The postintervention study group consisted of patients admitted for 10 weeks after the completion of the interventions (weeks 16-25). A timeline of the study events is shown in Figure 1.

Patient demographics and hospital-stay metrics determined a priori were attained via the Cedars-Sinai Enterprise Information Services core. Age, sex, medical 
Table 2. Patient Demographics in Control and Postintervention Groups

\begin{tabular}{lll}
\hline Patient demographic & Control $(\mathbf{n = 1 8 7})$ & Postintervention $(\mathbf{n = 1 6 6 )}$ \\
\hline Median age (IQR), y & $82.0(87.0-74.5)$ & $81.0(86.8-71.0)$ \\
\hline Male, n (\%) & $74(39.6)$ & $89(53.6)$ \\
\hline Charlson Comorbidity Index, median (IQR) & $6.0(8.0-5.0)$ & $6.0(8.0-5.0)$ \\
\hline Surgery with anesthesia, n (\%) & $24(12.8)$ & $27(16.3)$ \\
\hline IQR, interquartile range. & & \\
\hline
\end{tabular}

history, and incidence of surgery with anesthesia during hospitalization were recorded. The Charlson Comorbidity Index was calculated from patients' listed diagnoses following discharge. Primary outcomes included incidence of patients with delirium during hospitalization, percentage of tested shifts with positive CAM screens, length of hospital stay, and survival. Secondary outcomes included measures associated with delirium, including the use of chemical restraints, physical restraints, sitters, indwelling urinary catheters, and new psychiatry and neurology consults. Chemical restraints were defined as administration of a new antipsychotic medication or benzodiazepine for the specific indication of hyperactive delirium or agitation.

Statistical analysis was conducted by a statistician, using $\mathrm{R}$ version 3.6.3..$^{10} \mathrm{P}$ values of $<.05$ were considered significant. Categorical variables were analyzed using Fisher's exact test. Continuous variables were analyzed with Welch's $t$-test or, for highly skewed continuous variables, with Wilcoxon rank-sum test or Mood's median test. All patient data were anonymized and stored securely in accordance with institutional guidelines.

Our project was deemed to represent nonhuman subject research and therefore did not require Institutional Review Board (IRB) approval upon review by our institution's IRB committee and Office of Research Compliance and Quality Improvement. Standards for Quality Improvement Reporting Excellence (SQUIRE 2.0) guidelines were adhered to (Supplementary File can be found at mdedge.com/jcomjournal).

\section{Results}

We evaluated 353 patients who met our inclusion criteria: 187 in the control group, and 166 in the postintervention group. Ten patients were readmitted to the ward after their initial discharge; only the initial admission encounters were included in our analysis. Median age, sex, median Charlson Comorbidity Index, and incidence of surgery with anesthesia during hospitalization were comparable between the control and postintervention groups and are summarized in Table 2. In the control group, 1572 CAMs were performed, with 74 positive CAMs recorded among 27 patients with delirium. In the postintervention group, 1298 CAMs were performed, with 12 positive CAMs recorded among 7 patients with delirium (Figure 2). Primary and secondary outcomes, as well as CAM compliance measures, are summarized in Table 3.

Compared to the control group, the postintervention group had a significant decrease in the incidence of delirium during hospitalization ( $14.4 \%$ vs $4.2 \%, P=.002$ ) and a significant decrease in the mean percentage of tested nursing shifts with 1 or more positive CAM (4.9\% vs $1.1 \%, P=.002)$. Significant differences in secondary outcomes between the control and postintervention groups included median length of stay ( 6 days vs 4 days, $P=.004$ ), mean length of stay (8.5 days vs 5.9 days, $P=.003)$, and use of an indwelling urinary catheter $(9.1 \%$ vs $2.4 \%, P=.012)$. There was a trend towards decreased incidence of chemical restraints and psychiatry consults, which did not reach statistical significance. Differences in mortality during hospitalization, physical restraint use, and sitter use could not be assessed due to low incidence.

Compliance with nursing CAM assessments was evaluated. Compared to the control group, the postintervention group saw a significant increase in the percentage of shifts with a CAM performed (54.7\% vs $69.1 \%, P<.001)$. The median and mean number of CAMs performed per 


\section{Prevention of Hospital Delirium}

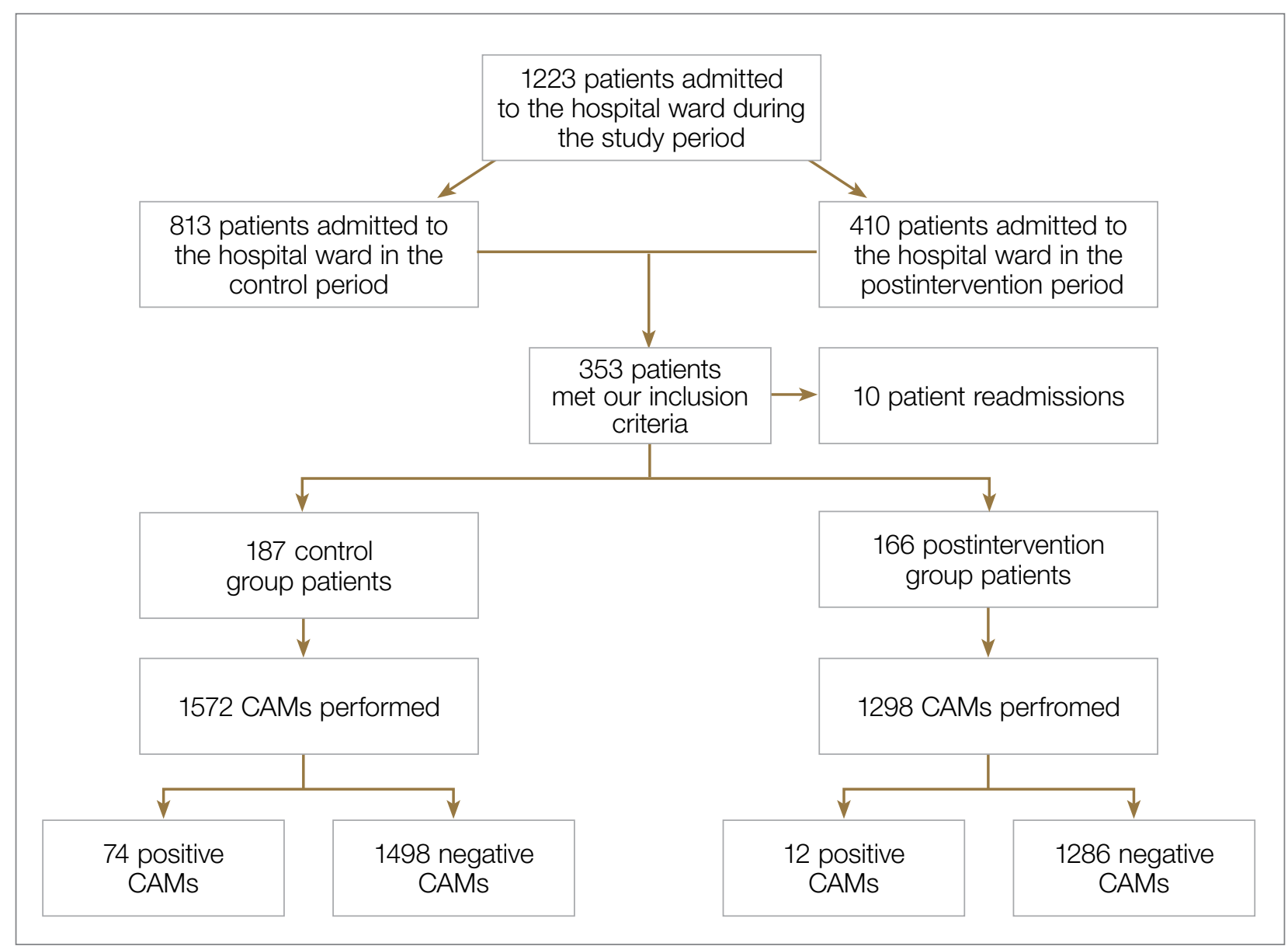

Figure 2. Flowchart of included patients and CAMs performed. The number of patients admitted to the hospital ward and who met our inclusion criteria are separated into control and postintervention groups. The number of CAMs performed and CAM results in each group are listed.

CAM, Confusion Assessment Method.

patient were similar between the control and postintervention groups.

Results of nursing surveys completed before and after the training program are listed in Table 4. After training, nurses had a greater level of confidence with recognizing delirium risk factors, preventing delirium, addressing delirium, utilizing the CAM tool, and educating others about delirium.

\section{Discussion}

Our study utilized a standardized delirium assessment tool to compare patient cohorts before and after nurse-targeted training interventions on delirium recognition and prevention. Our interventions emphasized nonpharmacologic intervention strategies, which are recommended as first-line in the management of patients with delirium. ${ }^{11}$ Patients were not excluded from the analysis based on preexisting medical conditions or recent surgery with anesthesia, to allow for conditions that are representative of community hospitals. We also did not use an inclusion criterion based on age; however, the majority of our patients were greater than 70 years old, representing those at highest risk for delirium. ${ }^{2}$ Significant outcomes among patients in the postintervention group include decreased incidence of delirium, lower average length of stay, decreased indwelling urinary catheter use, and increased compliance with delirium screening by nursing staff. 
Table 3. Statistical Results of Primary Outcome, Secondary Outcome, and CAM Compliance Measures Among Control and Postintervention Groups

\begin{tabular}{lllll}
\hline Primary outcomes & $\begin{array}{l}\text { Control } \\
(\mathbf{n = 1 8 7 )}\end{array}$ & $\begin{array}{l}\text { Postintervention } \\
(\mathbf{n = 1 6 6 )}\end{array}$ & $\boldsymbol{P}$ value & Statistical test performed \\
\hline $\begin{array}{l}\text { Incidence of patients with delirium during } \\
\text { hospitalization, } \mathrm{n}(\%)\end{array}$ & $27(14.4)$ & $7(4.2)$ & .002 & Fisher's exact test \\
\hline $\begin{array}{l}\text { Percentage of tested shifts with } \geq 1 \text { positive } \\
\text { CAM, mean (SD) }\end{array}$ & $4.9(16.3)$ & $1.1(6.0)$ & .002 & Wilcoxon rank sum test
\end{tabular}

\section{Secondary outcomes}

Median length of stay (IQR), d

$6(9.0-3.0) \quad 4(7.0-3.0) \quad .004 \quad$ Mood's median test

\begin{tabular}{lllll}
\hline Mean length of stay (SD), d & $8.5(10.7)$ & $5.9(5.6)$ & .003 & Welch's two sample $t$-test \\
\hline Mortality during hospitalization, $\mathrm{n}(\%)$ & $2(1)$ & $0(0)$ & NA & NA \\
\hline Chemical restraint, $\mathrm{n}(\%)$ & $28(15.0)$ & $17(10.2)$ & .20 & Fisher's exact test \\
\hline Physical restraints, $\mathrm{n}(\%)$ & $2(1.1)$ & $0(0)$ & $\mathrm{NA}$ & NA \\
\hline Sitter use, $\mathrm{n}(\%)$ & $0(0)$ & $1(0.6)$ & $\mathrm{NA}$ & NA \\
\hline Indwelling urinary catheter use, $\mathrm{n}(\%)$ & $17(9.1)$ & $4(2.4)$ & .01 & Fisher's exact test \\
\hline Psych consult, $\mathrm{n}(\%)$ & $16(8.6)$ & $8(4.8)$ & .20 & Fisher's exact test \\
\hline Neuro consult, $\mathrm{n}(\%)$ & $74(39.6)$ & $74(44.6)$ & .39 & Fisher's exact test \\
\hline
\end{tabular}

CAM compliance measures

\begin{tabular}{lllll}
\hline $\begin{array}{l}\text { Percentage of shifts } \geq 6 \text { hours in length with a } \\
\text { CAM performed (SD) }\end{array}$ & $54.7(27.7)$ & $69.1(29.4)$ & $<.001$ & Welch's two sample t-test \\
$\begin{array}{l}\text { Number of CAMs performed per patient, } \\
\text { median (IQR) }\end{array}$ & $6.0(11.0-3.0)$ & $6.0(10.0-3.0)$ & NA & NA \\
\hline $\begin{array}{l}\text { Number of CAMs performed per patient, } \\
\text { mean (SD) }\end{array}$ & $8.4(13.3)$ & $7.8(6.9)$ & NA & NA
\end{tabular}

$\mathrm{IQR}$, interquartile range; NA, not applicable.

While the study's focus was primarily on delirium prevention rather than treatment, these strategies may also have conferred the benefit of reversing delirium symptoms. In addition to measuring incidence of delirium, our primary outcome of percentage of tested shifts with 1 or more positive CAM was intended to assess the overall duration in which patients had delirium during their hospitalization. The reduction in shifts with positive CAMs observed in the postintervention group is notable, given that a significant percentage of patients with hospital delirium have the potential for symptom reversibility. ${ }^{12}$

Multiple studies have shown that admitted patients who develop delirium experience prolonged hospital stays, often up to 5 to 10 days longer.12-14 The decreased incidence and duration of delirium in our postintervention group is a reasonable explanation for the observed decrease in average length of stay. Our study is in line with previously documented initiatives that show that nonpharmacologic interventions can effectively address downstream health and fiscal sequelae of hospital delirium. For example, a volunteer-based initiative named the Hospital Elder Life Program, from which elements in our order set were modeled after, demonstrated significant reductions in delirium incidence, length of stay, and health care costs. ${ }^{14-16}$ Other initiatives that focused on educational training for nurses to assess and prevent delirium have also demonstrated similar positive results. ${ }^{17-19}$ Our study provides a model for effective nursing-focused education that can be reproduced in the hospital setting.

Unlike some other studies, which identified delirium based only on physician assessments, our initiative utilized the CAM performed by floor nurses to identify delirium. While this method may have affected the sensitivity and specificity of the CAMs, it also conferred the 


\begin{tabular}{|c|c|c|c|c|}
\hline & $\begin{array}{l}\text { Before training } \\
\quad(n=28)\end{array}$ & $\begin{array}{l}\text { Standard } \\
\text { error }\end{array}$ & $\begin{array}{l}\text { After training } \\
(\mathrm{n}=29)\end{array}$ & $\begin{array}{l}\text { Standard } \\
\text { error }\end{array}$ \\
\hline A. I can recognize patients who are at risk for delirium. & 3.89 & 0.12 & 4.31 & 0.12 \\
\hline $\begin{array}{l}\text { B. I have adequate skills and knowledge to intervene to } \\
\text { prevent or mitigate delirium. }\end{array}$ & 3.79 & 0.16 & 4.28 & 0.11 \\
\hline $\begin{array}{l}\text { C. I have adequate skills and knowledge in caring for } \\
\text { patients with delirium. }\end{array}$ & 3.86 & 0.13 & 4.17 & 0.15 \\
\hline $\begin{array}{l}\text { D. I know how to assess patients for delirium using the CAM } \\
\text { tool included in the electronic medical record. }\end{array}$ & 3.11 & 0.20 & 4.45 & 0.11 \\
\hline $\begin{array}{l}\text { E. I feel comfortable educating family members about delirium } \\
\text { and how they can help the patient. }\end{array}$ & 3.64 & 0.19 & 4.28 & 0.15 \\
\hline
\end{tabular}

1 = strongly disagree, 2 = disagree, 3 = neutral, 4 = agree, 5 = strongly agree

advantage of recognizing, documenting, and intervening on delirium in real time, given that bedside nurses are often the first to encounter delirium. Furthermore, nurses were instructed to notify a physician if a patient had a new positive CAM, as reflected in Table 1.

Our study demonstrated an increase in the overall compliance with the CAM screening during the postintervention period, which is significant given the under-recognition of delirium by health care professionals..$^{20}$ We attribute this increase to greater realized importance and a higher level of confidence from nursing staff in recognizing and addressing delirium, as supported by survey data. While the increased screening of patients should be considered a positive outcome, it also poses the possibility that the observed decrease in delirium incidence in the postintervention group was in fact due to more CAMs performed on patients without delirium. Likewise, nurses may have become more adept at recognizing true delirium, as opposed to delirium mimics, in the latter period of the study.

Perhaps the greatest limitation of our study is the variability in performing and recording CAMs, as some patients had multiple CAMs recorded while others did not have any CAMs recorded. This may have been affected in part by the increase in COVID-19 cases in our hospital towards the latter half of the study, which resulted in changes in nursing assignments as well as patient comorbidities in ways that cannot be easily quantified. Given the limited size of our patient cohorts, certain outcomes, such as the use of sitters, physical restraints, and in-hospital mortality, were unable to be assessed for changes statistically. Causative relationships between our interventions and associated outcome measures are necessarily limited in a binary comparison between control and postintervention groups.

Within these limitations, our study demonstrates promising results in core dimensions of patient care. We anticipate further quality improvement initiatives involving greater numbers of nursing staff and patients to better quantify the impact of nonpharmacologic nursingcentered interventions for preventing hospital delirium.

\section{Conclusion}

A multimodal strategy involving nursing-focused training and nonpharmacologic interventions to address hospital delirium is associated with improved patient care outcomes and nursing confidence. Nurses play an integral role in the early recognition and prevention of hospital delirium, which directly translates to reducing burdens in both patient functionality and health care costs. Education and tools to equip nurses to perform standardized delirium screening and interventions should be prioritized.

Corresponding author: Jason Ching, MD, Department of Neurology, Cedars-Sinai Medical Center, 8700 Beverly Blvd, Los Angeles, CA 90048; jason.ching@cshs.org.

Financial disclosures: None.

doi:10.12788/jcom.0071 


\section{References}

1. American Psychiatric Association. Diagnostic and Statistical Manual of Mental Disorders, 5th edition. American Psychiatric Association; 2013.

2. Vasilevskis EE, Han JH, Hughes CG, et al. Epidemiology and risk factors for delirium across hospital settings. Best Pract Res Clin Anaesthesiol. 2012;26(3):277-287. doi:10.1016/j.bpa.2012.07003

3. Leslie DL, Marcantonio ER, Zhang Y, et al. One-year health care costs associated with delirium in the elderly population. Arch Intern Med. 2008;168(1):27-32. doi:10.1001/archinternmed.2007.4

4. McCusker J, Cole M, Abrahamowicz M, et al. Delirium predicts 12-month mortality. Arch Intern Med. 2002;162(4):457-463. doi:10.1001/archinte.162.4.457

5. Witlox J, Eurelings LS, de Jonghe JF, et al. Delirium in elderly patients and the risk of postdischarge mortality, institutionalization, and dementia: a meta-analysis. JAMA. 2010;304(4):443-451. doi:10.1001/jama.2010.1013

6. Gross $\mathrm{AL}$, Jones $\mathrm{RN}$, Habtemariam DA, et al. Delirium and long-term cognitive trajectory among persons with dementia. Arch Intern Med. 2012;172(17):1324-1331. doi:10.1001/archinternmed.2012.3203

7. Inouye SK. Prevention of delirium in hospitalized older patients: risk factors and targeted intervention strategies. Ann Med. 2000;32(4):257-263. doi:10.3109/07853890009011770

8. Siddiqi N, Harrison JK, Clegg A, et al. Interventions for preventing delirium in hospitalised non-ICU patients. Cochrane Database Syst Rev. 2016;3:CD005563. doi:10.1002/14651858.CD005563.pub3

9. Inouye SK, van Dyck $\mathrm{CH}$, Alessi CA, et al. Clarifying confusion: the confusion assessment method. A new method for detection of delirium. Ann Intern Med. 1990;113(12):941-948. doi:10.7326/0003-4819-113-12-941

10. R Core Team. R: A Language and Environment for Statistical Computing. R Foundation for Statistical Computing; 2017.

11. Fong TG, Tulebaev SR, Inouye SK. Delirium in elderly adults: diag- nosis, prevention and treatment. Nat Rev Neurol. 2009;5(4):210220. doi:10.1038/nrneurol.2009.24

12. Siddiqi N, House AO, Holmes JD. Occurrence and outcome of delirium in medical in-patients: a systematic literature review. Age Ageing. 2006;35(4):350-364. doi:10.1093/ageing/afl005

13. Ely EW, Shintani A, Truman B, et al. Delirium as a predictor of mortality in mechanically ventilated patients in the intensive care unit. JAMA. 2004;291(14):1753-1762. doi:10.1001/jama.291.14.1753

14. Chen CC, Lin MT, Tien YW, et al. Modified Hospital Elder Life Program: effects on abdominal surgery patients. J Am Coll Surg. 2011;213(2):245-252. doi:10.1016/j.jamcollsurg.2011.05.004

15. Zaubler TS, Murphy K, Rizzuto L, et al. Quality improvement and cost savings with multicomponent delirium interventions: replication of the Hospital Elder Life Program in a community hospital. Psychosomatics. 2013;54(3):219-226. doi:10.1016/j.psym.2013.01.010

16. Rubin FH, Neal K, Fenlon K, et al. Sustainability and scalability of the Hospital Elder Life Program at a community hospital. J Am Geriatr Soc. 2011;59(2):359-365. doi:10.1111/j.1532-5415.2010.03243.x

17. Milisen K, Foreman MD, Abraham IL, et al. A nurse-led interdisciplinary intervention program for delirium in elderly hipfracture patients. J Am Geriatr Soc. 2001;49(5):523-532. doi:10.1046/j.1532-5415.2001.49109.x

18. Lundström M, Edlund A, Karlsson S, et al. A multifactorial intervention program reduces the duration of delirium, length of hospitalization, and mortality in delirious patients. J Am Geriatr Soc. 2005;53(4):622-628. doi:10.1111/j.1532-5415.2005.53210.x

19. Tabet N, Hudson S, Sweeney $\mathrm{V}$, et al. An educational intervention can prevent delirium on acute medical wards. Age Ageing. 2005;34(2):152-156. doi:10.1093/ageing/afi031

20. Han JH, Zimmerman EE, Cutler $\mathrm{N}$, et al. Delirium in older emergency department patients: recognition, risk factors, and psychomotor subtypes. Acad Emerg Med. 2009;16(3):193-200. doi:10.1111/j.1553-2712.2008.00339.x 


\section{Revised Standards for Quality Improvement Reporting Excellence (SQUIRE 2.0)}

\section{September 15, 2015}

\begin{tabular}{|c|c|c|}
\hline $\begin{array}{c}\text { Text Section and Item } \\
\text { Name }\end{array}$ & Section or Item Description & \\
\hline Notes to authors & $\begin{array}{l}\text { The SQUIRE guidelines provide a framework for } \\
\text { reporting new knowledge about how to improve } \\
\text { healthcare } \\
\text { - The SQUIRE guidelines are intended for reports that } \\
\text { describe system level work to improve the quality, } \\
\text { safety, and value of healthcare, and used methods to } \\
\text { establish that observed outcomes were due to the } \\
\text { intervention(s). } \\
\text { - A range of approaches exists for improving } \\
\text { healthcare. SQUIRE may be adapted for reporting } \\
\text { any of these. } \\
\text { - Authors should consider every SQUIRE item, but it } \\
\text { may be inappropriate or unnecessary to include } \\
\text { every SQUIRE element in a particular manuscript. } \\
\text { - The SQUIRE Glossary contains definitions of many } \\
\text { of the key words in SQUIRE. } \\
\text { - The Explanation and Elaboration document provides } \\
\text { specific examples of well-written SQUIRE items, } \\
\text { and an in-depth explanation of each item. } \\
\text { Please cite SQUIRE when it is used to write a } \\
\text { manuscript. }\end{array}$ & $\begin{array}{l}\text { As you review the } \\
\text { manuscript, place a } \\
\text { checkmark in this } \\
\text { column for each } \\
\text { SQUIRE item that is } \\
\text { appropriately } \\
\text { addressed in the } \\
\text { manuscript. } \\
\text { Remember that not } \\
\text { every item is } \\
\text { necessary in every } \\
\text { manuscript. }\end{array}$ \\
\hline \multicolumn{3}{|l|}{ Title and Abstract } \\
\hline 1. Title & $\begin{array}{l}\text { Indicate that the manuscript concerns an initiative to } \\
\text { improve healthcare (broadly defined to include the quality, } \\
\text { safety, effectiveness, patient-centeredness, timeliness, cost, } \\
\text { efficiency, and equity of healthcare) }\end{array}$ & \\
\hline 2. Abstract & $\begin{array}{l}\text { a. Provide adequate information to aid in searching and } \\
\text { indexing } \\
\text { b. Summarize all key information from various sections of } \\
\text { the text using the abstract format of the intended } \\
\text { publication or a structured summary such as: } \\
\text { background, local problem, methods, interventions, } \\
\text { results, conclusions }\end{array}$ & \\
\hline
\end{tabular}




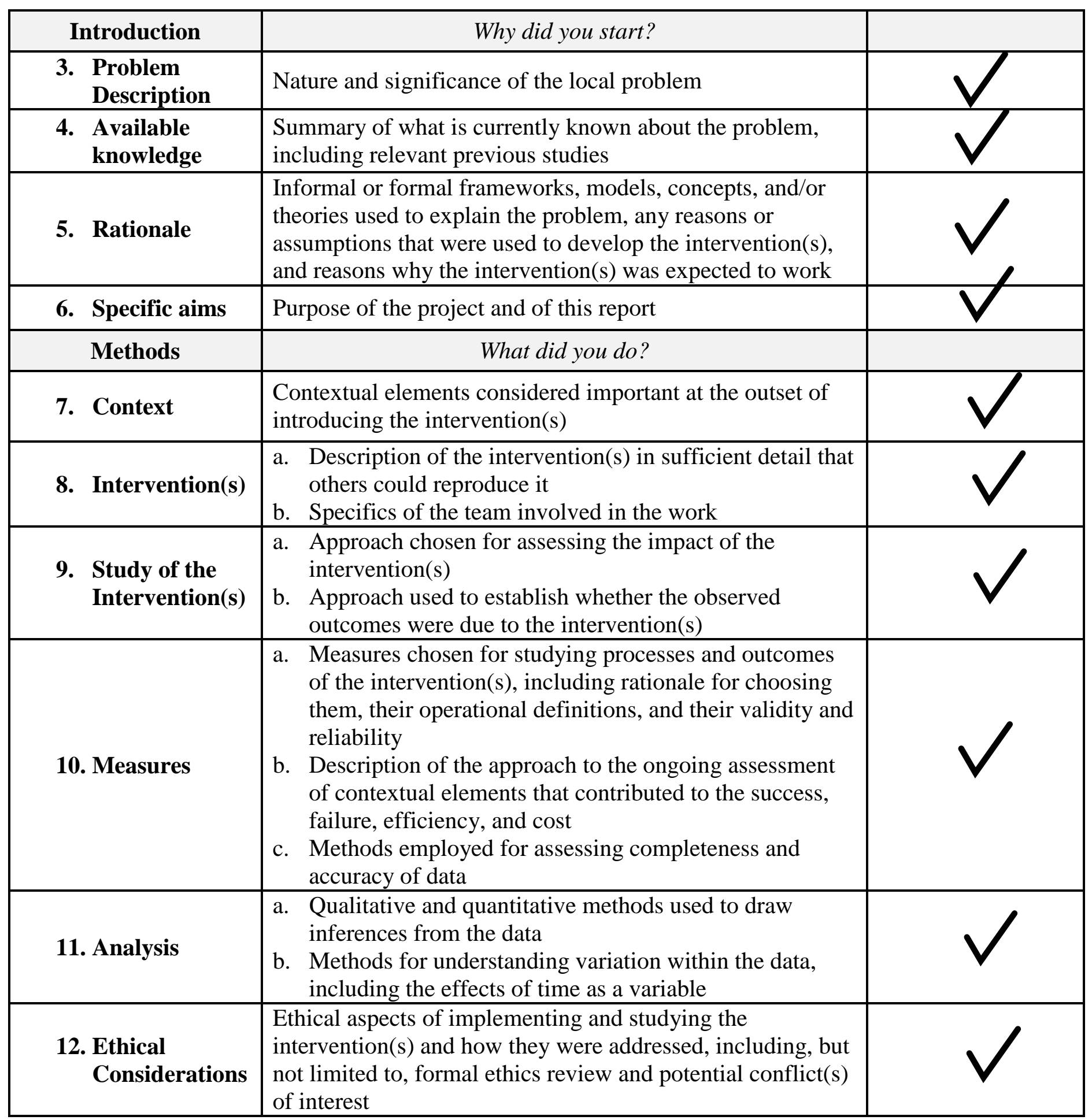




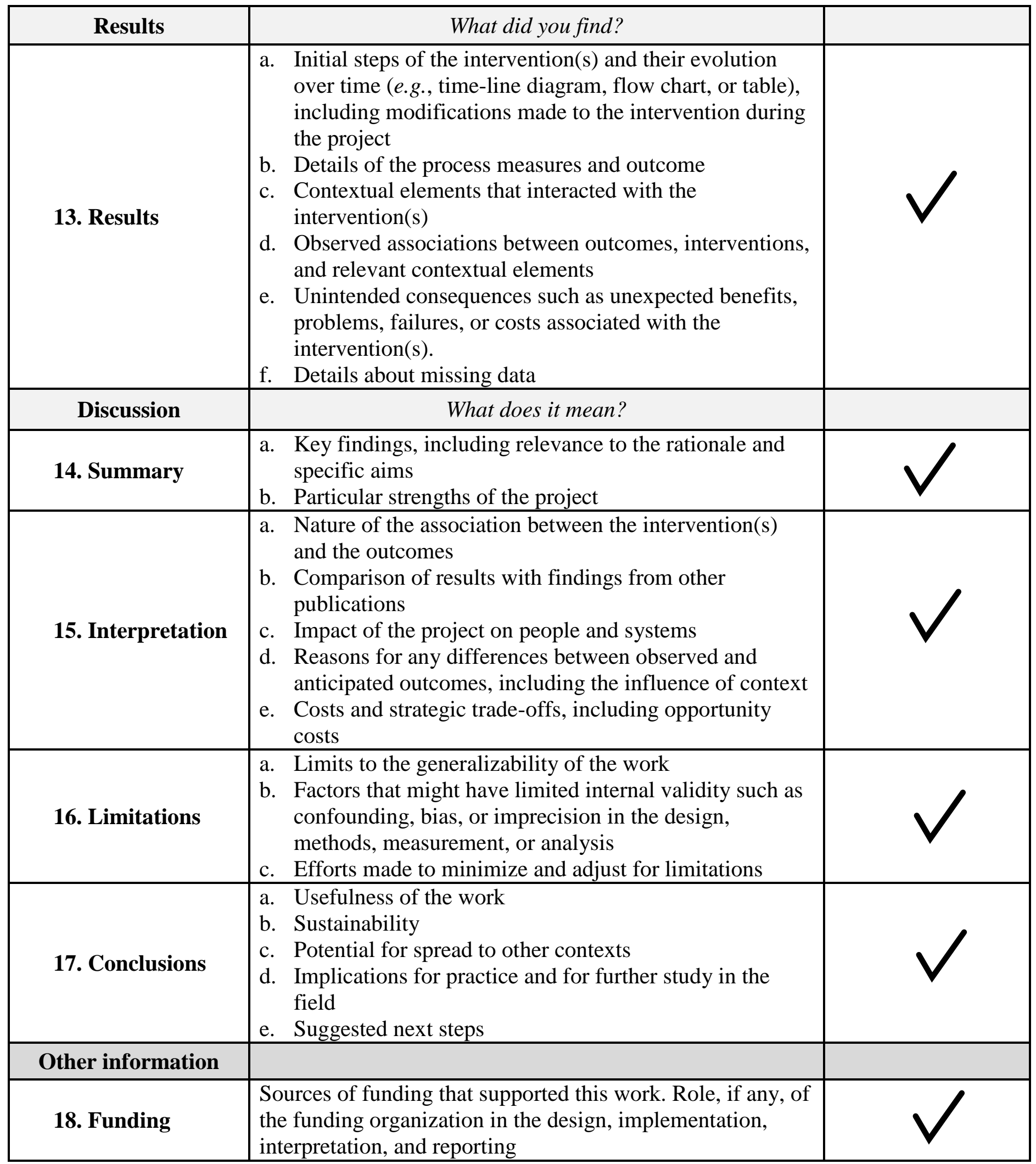

